\title{
Palmeiras (Arecaceae) nativas no município de Campo Mourão, Paraná, Brasil
} Native palms (Arecaceae) of Campo Mourão municipality, Paraná, Brazil

\author{
Marcelo Galeazzi Caxambú ${ }^{1,3}$, Henrique Cesar Lopes Geraldino ${ }^{1}$, Greta Aline Dettke ${ }^{1,3}$, Ana Raquel da \\ Silva ${ }^{2}$, Eloiza Nunes dos Santos ${ }^{1}$
}

\begin{abstract}
Resumo
As palmeiras são um dos elementos típicos das florestas tropicais. No Paraná, Arecaceae está representada por 23 espécies, distribuídas por todas as formações vegetais. Este estudo objetiva o levantamento das palmeiras nativas do município de Campo Mourão, Paraná, promovendo mais informações sobre a biologia das espécies confirmadas. O estudo foi realizado em áreas de Floresta Estacional Semidecidual e Floresta Ombrófila Mista e remanescentes de Cerrado, além da consulta dos acervos dos herbários FUEL, HCF, MBM e SP. Foram confirmadas sete espécies: Acrocomia hassleri; Allagoptera campestris; Butia microspadix, B. paraguayensis; Euterpe edulis; Geonoma schottiana e Syagrus romanzoffiana. O elevado número de representantes das Arecaceae encontrados deve-se à diversidade florística proporcionada pelas três diferentes tipologias de vegetação do município. Tendo em vista o alto grau de destruição do Cerrado em Campo Mourão, alerta-se sobre o risco de extinção de A. hassleri e B. paraguayensis no Paraná. Butia microspadix não foi reencontrada nos remanescentes, estando provavelmente extinta no município. Acrocomia emensis, não teve sua ocorrência confirmada para o Paraná. Dentre as espécies florestais, E. edulis e G. schottiana também apresentam número reduzido de populações e necessitam ações que garantam sua proteção.

Palavras-chave: Arecaceae, Cerrado, conservação, extinção, floresta tropical.
\end{abstract}

\begin{abstract}
Palms a typical element of tropical forests. In Paraná state, Arecaceae is represented by 23 species, distributed in all vegetation types. This study aimed to survey the native palms in Campo Mourão, Paraná, and provide more information on the biology of confirmed species. The study was conducted in areas of Subtropical Seasonal Forest, Subtropical Mixed Forest (with Araucaria) and Tropical Savanna remnants (Cerrado), as well as collections from the herbaria FUEL, HCF, MBM and SP. Seven species were confirmed: Acrocomia hassleri (Barb. Rodr.) W.J. Hahn; Allagoptera campestris (Mart.) Kuntze; Butia microspadix Burret, B. paraguayensis (Barb. Rodr.) L.H. Bailey; Euterpe edulis Mart.; Geonoma schottiana Mart. and Syagrus romanzoffiana (Cham.) Glassman. The three different vegetation types found in Campo Mourão are the source of the high number of Arecaceae species found. Due to the great degree of destruction of the Cerrado in Campo Mourão, A. hassleri and B. paraguayensis are at risk of extinction. Butia microspadix was not found in the remnants and was considered extinct in the municipality. One species, Acrocomia emensis (Toledo) Lorenzi, was not been confirmed for Paraná state. Among the forest species, E. edulis and G. schottiana also have a small number of populations and require action to ensure protection.
\end{abstract}

Key words: Arecaceae, Cerrado, conservation, extinction, tropical forest.

\section{Introdução}

Arecaceae é representada por cerca de 2600 espécies distribuídas em mais de 240 gêneros (Lorenzi et al. 2004). No Brasil estão presentes cerca de 270 espécies e 38 gêneros nativos (Leitman et al. 2014). São monocotiledôneas consideradas características da flora tropical e comuns nas formações florestais Ásia, Indonésia, Ilhas do Pacífico e Américas (Lorenzi et al. 2004).

$\mathrm{Na}$ maioria das florestas neotropicais, as palmeiras destacam-se pela abundância e riqueza de espécies, tanto no sub-bosque quanto nos estratos

\footnotetext{
${ }^{1}$ Universidade Tecnológica Federal do Paraná, Herbário HCF, Rodovia BR-369 km 0,5, C.P. 271, 87301-005, Campo Mourão, PR.

${ }^{2}$ Universidade Federal do Paraná, Campus Jardim Botânico, Av. Pref. Lothário Meissner 900, 80210-170, Curitiba, PR.

${ }^{3}$ Autores para correspondência: gretadet@yahoo.com.br; mcaxambu@utfpr.edu.br
} 
superiores. A presença de diversos micro-habitats em sua arquitetura possibilita a sua utilização por vários grupos de animais e são consideradas espécies-chave em vários ecossistemas (Bates 1988; Alonso et al. 2001; Santos et al. 2003).

Em algumas formações vegetacionais as palmeiras são responsáveis pela caracterização do ambiente, vivendo em densas populações como os buritizais (Mauritia flexuosa L.f) no Brasil central, carnaubais (Copernicia prunifera (Mill.) H.E. Moore) no nordeste brasileiro, e babaçuais (Attalea speciosa Mart. ex Spreng.), ocorrendo nestes dois ambientes. No Sul do Brasil, ocorrem algumas áreas contínuas ou relictuais de butiazais como, por exemplo, no Rio Grande do Sul as espécies de Butia catarinensis Noblick \& Lorenzi (butiazais de Torres), B. odorata (Barb. Rodr.) Noblick (butiazais de Tapes) e B. yatay (Mart.) Becc. (butiazais de Coatepe) (Soares et al. 2014). Já em outros locais, onde não são tão abundantes, como na Floresta Ombrófila Mista do Sul do país, aparecem em lugares de forte insolação, ao longo do limite da floresta ou no interior da Floresta Ombrófila Densa e Floresta Estacional (Romariz 1996).

As palmeiras possuem representantes dióicos ou monóicos; as raízes podem ser subterrâneas ou aéreas; e os estipes podem ser solitários, cespitosos ou raramente escandentes, aéreos ou subterrâneos, lisos ou densamente cobertos por espinhos; as folhas encontram-se agrupadas no ápice do estipe, são simples, pinatipartidas ou flabeliformes, palminérveas ou com segmentos foliares paralelinérveos, com bainhas abertas ou fechadas e pecíolos curtos ou longos; as inflorescências, interfoliares ou infrafoliares apresentam-se em forma de espiga, racemos ou panículas; as flores são geralmente trímeras e sésseis; os frutos apresentam pericarpo liso ou espinescente, carnoso e/ou fibroso, o endocarpo geralmente é duro e contém, no seu interior, uma ou mais sementes (Miranda et al. 2001; Gonçalves \& Lorenzi 2007; Lorenzi et al. 2010).

Para o Paraná são relatadas 23 espécies de Arecaceae (Leitman et al. 2014), das quais três figuram na Lista Vermelha Estadual de Espécies da Flora Ameaçadas de Extinção (Hatschbach \& Ziller 1995), na categoria: em perigo Butia paraguayensis (Barb. Rodr.) Bailey, rara: Syagrus hatschbachii Glassman (= Butia microspadix Burret) e vulnerável: Trithrinax brasiliensis (Burm.) Drude \& Griseb.; e quatro no Livro Vermelho da Flora do Brasil (Leitman et al. 2013), categoria vulnerável: Acrocomia emensis (Toledo) Lorenzi,
Butia eriospatha (Mart. ex Drude) Becc., Butia microspadix Burret e Euterpe edulis Mart.

No município de Campo Mourão as principais formações vegetacionais encontradas são Floresta Estacional Semidecidual, Floresta Ombrófila Mista e Cerrado. No estado do Paraná, as regiões norte e oeste e os vales dos rios formadores da bacia do Rio Paraná, abaixo dos 800 metros de altitude, definem a região com Floresta Estacional Semidecidual. Na porção oeste da Serra do Mar, ocupando as áreas planálticas do Estado, localiza-se a região com Floresta Ombrófila Mista, ocorrendo entre 800 e 1200 metros de altitude. Na região oeste do Paraná, a Floresta Ombrófila Mista e a Floresta Estacional Semidecidual podem ser encontradas na forma de um ecótono, caracterizado como a interpenetração de espécies características das duas grandes unidades geográficas existentes (Roderjan et al. 2002). O Cerrado ocorre no estado na forma de fragmentos relictuais, incorporados às formações florestais e representam o limite austral desta vegetação na América, apresentando fisionomia e florística similar àquelas dos planaltos do Brasil central (Roderjan et al. 2002). As maiores áreas se situam no Primeiro e Segundo Planaltos Paranaenses e no Terceiro Planalto são encontrados apenas pequenos fragmentos nos municípios de Astorga, Campo Mourão, Cianorte e Cruzeiro do Oeste, cuja área total original somava menos de $150 \mathrm{~km}^{2}$ (Hatschbach et al. 2005). Atualmente esta área está bastante reduzida devido ao avanço das áreas urbanas e das monoculturas.

Tendo em vista a importância ecológica dessa família dentro dos ecossistemas, este estudo teve como objetivo realizar um levantamento das Arecaceae nativas no município de Campo Mourão, Paraná, e para as espécies confirmadas elaborar uma chave de identificação, apresentar descrições, dados ecológicos e informar a atual situação de conservação das populações.

\section{Material e Métodos}

O estudo foi realizado no município de Campo Mourão (Fig. 1), com sede localizada nas coordenadas $24^{\circ} 02^{\prime} \mathrm{S} / 52^{\circ} 22^{\prime} \mathrm{W}$, na porção Centro Ocidental do Paraná, geomorfologicamente denominada como Terceiro Planalto Paranaense (IBGE 1997). O clima, de acordo com a classificação climática de Köppen, é Cfa: clima subtropical úmido mesotérmico, com verões quentes e geadas pouco freqüentes, com tendência de concentração das chuvas nos meses de verão, sem estação seca definida, com as seguintes médias anuais: 
temperatura dos meses mais quentes superior a $22^{\circ} \mathrm{C}$ e dos meses mais frios inferior a $18^{\circ} \mathrm{C}$; temperatura média de aproximadamente $20^{\circ} \mathrm{C}$; chuvas variando entre 1.300 e $1.600 \mathrm{~mm}$; umidade relativa do ar $75 \%$; índice hídrico entre os níveis 20 e 60 e ausência de deficiência hídrica. Os ventos predominantes na região são os de quadrante nordeste, apresentando probabilidade de geadas nos meses de inverno, quando sopram de sul e sudoeste (Maack 1981). Os solos da região são desenvolvidos a partir de rochas eruptivas básicas, considerados de grande aptidão agrícola. As classes mais comumente encontradas são os Latossolos Vermelhos, Nitossolos Vermelhos,
Cambissolos, e Neossolos Litólicos e Regolíticos (EMBRAPA 1999).

As três formações vegetacionais encontradas no município de Campo Mourão, o Cerrado, a Floresta Ombrófila Mista e a Floresta Estacional Semidecidual, formam áreas de ecótono entre elas. A vegetação de Cerrado originalmente foi a mais abundante no município, com cerca de $102 \mathrm{~km}^{2}$ (Maack 1981). O perímetro urbano situa-se em meio a um divisor de águas no qual a vegetação desenvolvia-se na forma de Cerrado stricto sensu, e emáreas adjacentes a esse local na forma de cerradões, como vegetação ripária e composição mista, ao norte
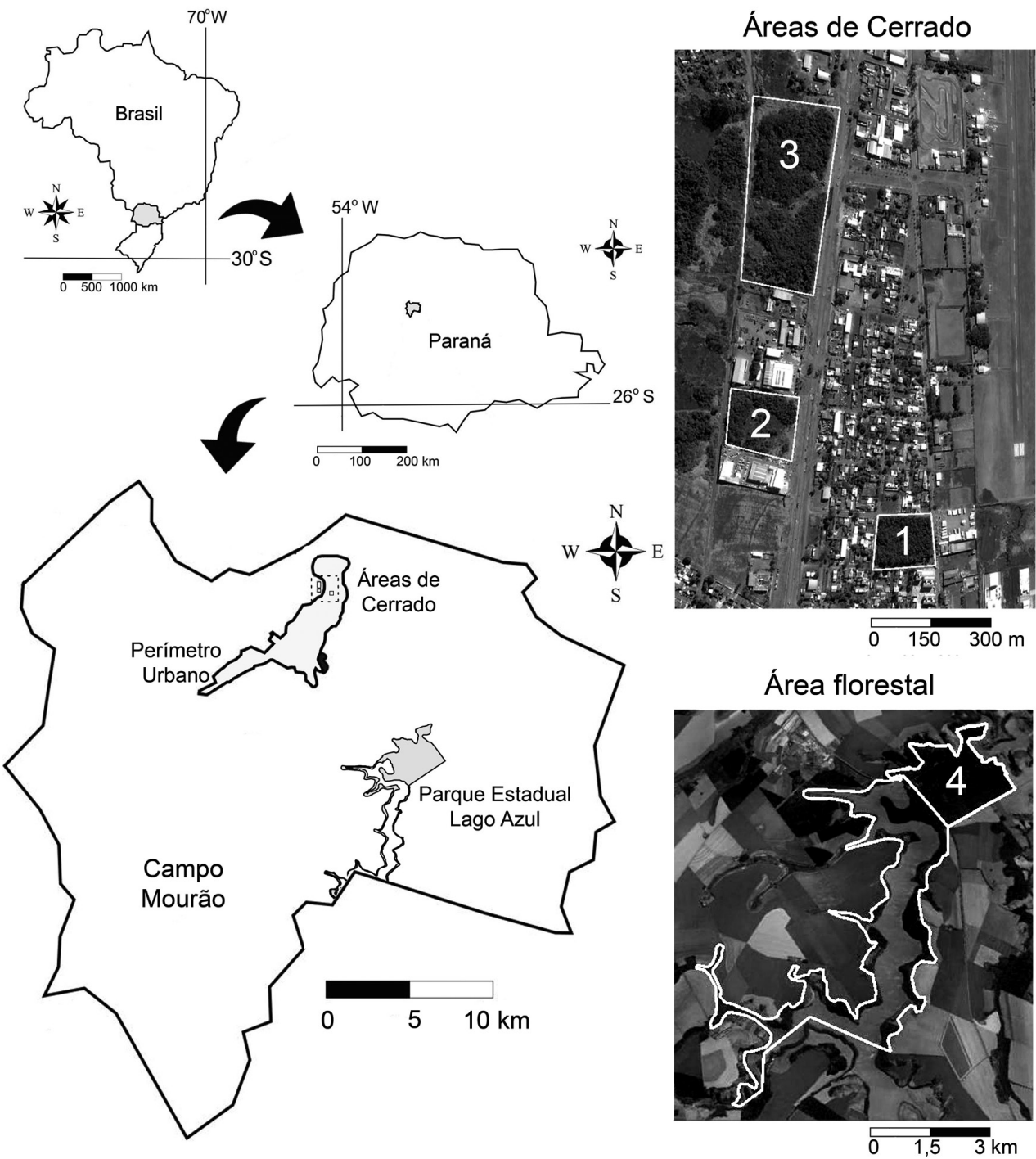

Figura 1 - Localização do município de Campo Mourão, Paraná, Brasil e áreas de coletas. À direita imagens de satélite de Google Earth ${ }^{\circledR}$.

Figure 1 - Localization of Campo Mourão, Paraná, Brazil and collection areas. Satellite images from Google Earth ${ }^{\circledR}$. 
com a Floresta Estacional Semidecidual e ao sul com a Floresta Ombrófila Mista (Guerreiro et al. 2011). Atualmente, devido à expansão da área urbana restam pequenos fragmentos bordeando as rodovias ou lotes abandonados, onde ainda podem ser encontradas espécies típicas do Cerrado. Destes apenas $13.318 \mathrm{~m}^{2}$ são preservados por lei (Decreto Municipal 596/93) na Estação Ecológica do Cerrado de Campo Mourão e outra área, denominada Lote 7-H, com $13.300 \mathrm{~m}^{2}$, encontra-se em processo de desapropriação (Lei Municipal 1769/03). As fisionomias florestais do município foram continuamente substituídas por monoculturas de soja, milho, aveia ou eucalipto e, atualmente, se encontram margeando os rios ou em pequenos fragmentos, alguns instituídos como Reserva Particular do Patrimônio Natural (RPPN). O Parque Estadual Lago Azul, cuja principal área situase em Campo Mourão, incorpora principalmente áreas de Floresta Estacional Semidecidual e Floresta Ombrófila Mista, além de pequenos enclaves marginais de Cerrados já bastante descaracterizados.

O levantamento foi conduzido através de observações em campo e coletas de material botânico entre os anos de 2003 e 2013, além da consulta aos acervoa dos herbários FUEL, HCF, MBM e SP. O material coletado foi depositado no Herbário da Universidade Tecnológica Federal do Paraná, Campus Campo Mourão (HCF).

Além de coletas esporádicas em toda a área do município, foram visitadas intensivamente áreas remanescentes de Cerrado - 1) Estação Ecológica do Cerrado Prof a . Diva Aparecida Camargo (13.318 $\left.\mathrm{m}^{2}, 24^{\circ} 01^{\prime} \mathrm{S} / 52^{\circ} 21^{\prime} \mathrm{W}\right) ;$ 2) Lote $7-\mathrm{H}$, Cerrado Valtra (13.300 $\left.\mathrm{m}^{2}, 2^{\circ} 00^{\prime} \mathrm{S} / 52^{\circ} 21^{\prime} \mathrm{W}\right), 3$ ) Lote particular, Cerrado dos Perdoncini (6,4 ha, $\left.24^{\circ} 00^{\prime} \mathrm{S} / 52^{\circ} 21^{\prime} \mathrm{W}\right)$ e área remanescente de vegetação florestal -4) Parque Estadual do Lago Azul (1.749 ha, destes $1.263,5$ ha correspondem a área de lâmina d'água, $\left.24^{\circ} 06^{\prime} \mathrm{S} / 52^{\circ} 18^{\prime} \mathrm{W}\right)$ (Fig. 1).

A descrição das espécies seguiu Lorenzi et al. (2010). Dados sobre o período de floração e frutificação foram obtidos através de bibliografias especializadas (Lorenzi et al. 2004; 2006; 2010) e informações presentes nas fichas das exsicatas de coletas realizadas no Paraná.

\section{Resultados e Discussão}

No município de Campo Mourão foram encontradas sete espécies de Arecaceae (Figs. 2 e 3), pertencentes a seis gêneros: Acrocomia, Allagoptera, Butia, Euterpe, Geonoma e Syagrus. O gênero Butia apresentou duas espécies e os demais uma espécie cada.

A Figura 4 apresenta os períodos de floração e frutificação dos táxons. A maioria das palmeiras estudadas apresenta inflorescências no inverno e primavera, nos meses de julho a dezembro, sendo que apenas Geonoma schottiana apresenta flores em época diferente das demais, nos meses de março a junho. Sobre a oferta de recursos à fauna, o maior tempo de disponibilidade de frutos nos cachos é de Geonoma schottiana, Euterpe edulis e Syagrus romanzoffiana. As demais possuem um período mais curto de frutificação, sendo a maioria no verão e Allagoptera campestris verão e outono.

\section{Chave de identificação das espécies de palmeiras nativas do município de Campo Mourão, Paraná, Brasil}

1. Bainha das folhas fechadas, envolvendo totalmente a região apical do caule (palmito)

1'. Bainha das folhas abertas

2. Bráctea da inflorescência com espinhos.

4.1. Euterpe edulis

2'. Bráctea da inflorescência sem espinhos

3. Inflorescência não ramificada, espiga

1.1. Acrocomia hassleri

3'. Inflorescência ramificada, racemos ou panículas

4. Caule revestido pelas bainhas das folhas deiscentes

5. Planta até $0,3 \mathrm{~m}$ de altura; inflorescência entre $25-40 \mathrm{~cm}$ compr

2.1. Allagoptera campestris

.................................................................................. 3.1. Butia microspadix

5'. Planta até $2 \mathrm{~m}$ de altura; inflorescências entre 45-60 cm compr

3.2. Butia paraguayensis

4'. Caule liso, apresentando somente as cicatrizes foliares

6. Caule até $3 \mathrm{~cm}$ diâm.; folhas 1,3-1,75 m compr.; frutos purpúreos ou negros quando maduros

5.1. Geonoma schottiana

6'. Caule 30-40 cm diâm.; folhas 2,7-4,7 m compr.; frutos amarelos ou alaranjados quando maduros 6.1. Syagrus romanzoffiana 

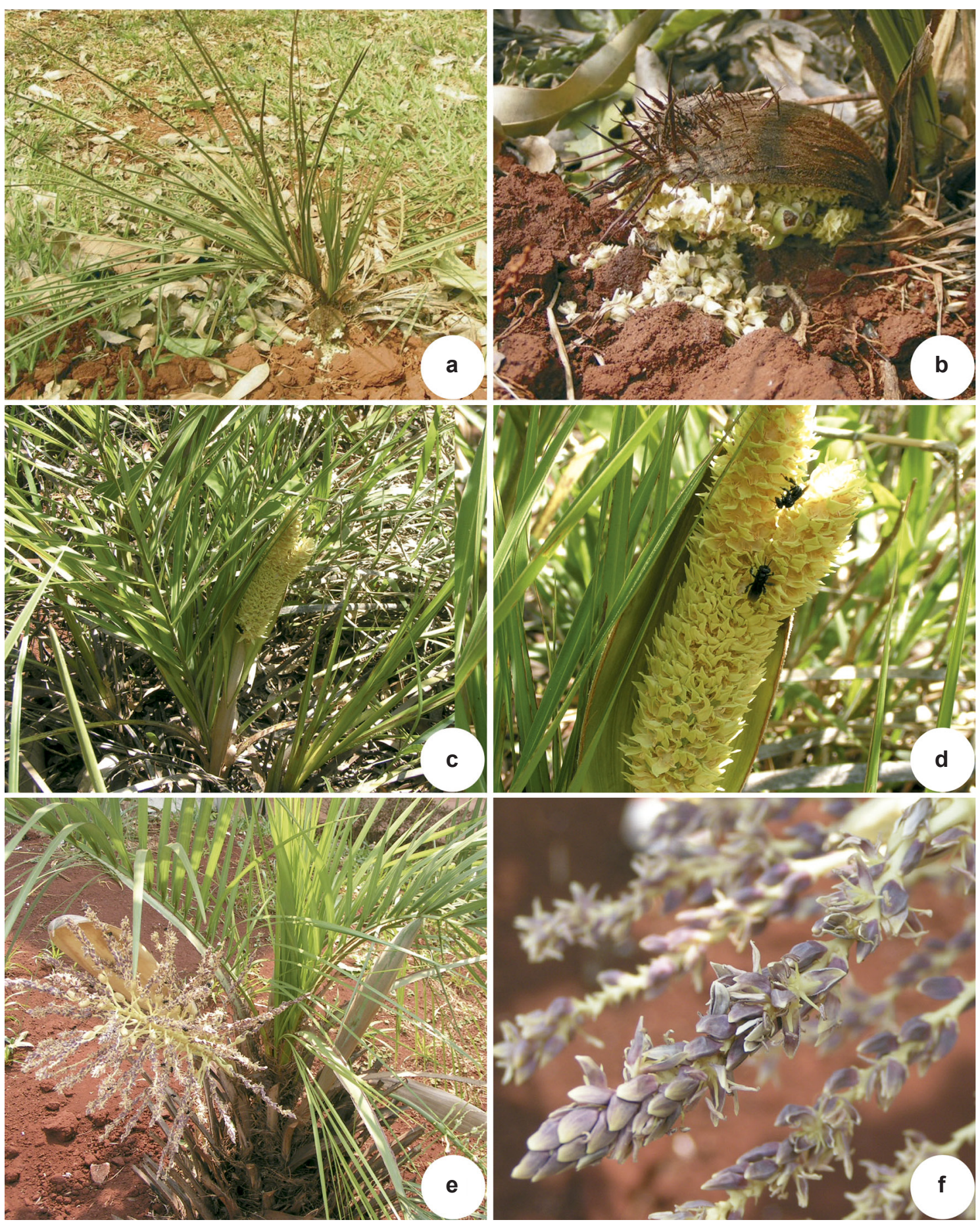

Figura 2 - a-b. Acrocomia hassleri - a. hábito; b. detalhe da bráctea peduncular aculeada e inflorescência. c-d. Allagoptera campestris - c. hábito; d. detalhe da inflorescência. e-f. Butia paraguayensis - e. hábito; f. detalhe das flores estaminadas. (Fotos: Acervo HCF).

Figure 2 - a-b. Acrocomia hassleri - a. habit; $\mathrm{b}$. detail of aculeate peduncular bract and inflorescence. c-d. Allagoptera campestris - $\mathrm{c}$. habit; d. detail of inflorescence. e-f. Butia paraguayensis - e. habit; f. detail of female flowers. (Photos: HCF photo collection). 
1. Acrocomia Mart., Palm. Fam. 22. 1824.

1.1 Acrocomia hassleri (Barb. Rodr.) W.J. Hahn, Principes, 35(3): 170, 1991.

Planta 40-80 cm alt.; armada. Caule subterrâneo, 30-100 cm compr., 2 cm diâm., solitário. Folhas pinatipartidas, $31-38 \mathrm{~cm}$ compr., emergindo na altura do solo; pecíolo $6-8 \mathrm{~cm}$ compr., tomentoso; bainhas não desenvolvidas; raque $25-30 \mathrm{~cm}$ compr., espinhos ao longo da raque, mais abundantes na base, $0,5-3 \mathrm{~cm}$ compr.; segmentos foliares $12-18$ pares, dispostos em dois planos, lanceolados, segmentos medianos 35-50 $\times 0,4-0,8 \mathrm{~cm}$. Inflorescência interfoliar, $6-8 \mathrm{~cm}$ compr., dispostas ao nível do solo, ramificada até primeira ordem; bráctea peduncular $8-9 \mathrm{~cm}$ compr., persistente, revestimento tomentoso castanho, espinhos presentes na porção mediana e/ou apical, 0,4-2,5 cm compr.; ramos florais 7-8, eretos, 5-7 $\mathrm{cm}$ compr. Flores sésseis, pistiladas e estaminadas na mesma inflorescência, as estaminadas no ápice, 5-6 mm compr., pistiladas na base, 5-7 $\mathrm{mm}$ compr. Fruto não visto.

Nomes populares: coquinho-do-campo, tucum-anão (Lorenzi et al. 2010).

Material examinado: Cerrado, 10.IX.2005, fl., V.M. Corneli 1 (HCF).

Acrocomia hassleri ocorre no Brasil e Paraguai (Jiménez \& Knapp 1998). No Brasil ocorre nos estados da Bahia, Goiás, Mato Grosso, Mato Grosso do Sul, Minas Gerais, Paraná e São Paulo (Leitman et al. 2014). São plantas espinescentes, com caule subterrâneo, que formam pequenas populações, associadas geralmente a áreas de cerrado, de solos bem drenados. No Paraná, é citada por Jiménez \& Knapp (1998) e por Leitman et al. (2014), sem especificação de local de coleta. Para o estado, encontramos somente a coleta apresentada neste estudo para o município de Campo Mourão. Foram localizados quatro indivíduos, um em remanescente de Cerrado (Lote 7-H) e três em lotes da área urbana que foram transplantados para o arboreto da UTFPR-Campus Campo Mourão.

Espécie caracterizada pelo caule subterrâneo e bráctea peduncular curta, tomentosa, com espinhos esparsos na região mediana e/ou apical. Pode ser confundida com A. emensis (Toledo) Lorenzi, que apresenta maior porte, bráctea peduncular maior que $15 \mathrm{~cm}$ compr., toda recoberta por espinhos (Lorenzi et al. 2010). No Livro Vermelho da Flora do Brasil, Leitman et al. (2013) mapeiam a ocorrência de A. emensis (categoria de ameaça vulnerável) para a região de Campo Mourão, porém não foi encontrado nenhum material da espécie para o município ou para o estado, que comprovem a sua ocorrência.

2. Allagoptera Nees, Flora 4: 296. 1821.

2.1 Allagoptera campestris (Mart.) Kuntze, Rev. Gen. Pl. 2: 726. 1891.

Planta 70-80 cm alt.; inerme. Caule subterrâneo, aprox. $5 \mathrm{~cm}$ compr., $3 \mathrm{~cm}$ diâm., solitário ou cespitoso. Folhas pinatipartidas, $65-88$ cm compr., emergindo na altura do solo; bainha não desenvolvida; pecíolo 5-8 cm compr., levemente coberto por escamas; raque $60-80 \mathrm{~cm}$ compr.; segmentos foliares 42-46 pares, dispostas em dois planos, lanceolados, segmentos medianos 20-30 × 0,9-1,2 cm. Inflorescência interfoliar, 50-65 cm compr., raro ramificada; 2 brácteas pedunculares, $30-45 \mathrm{~cm}$ compr., persistentes, a externa com 2-2,5 cm larg., a interna com 4,5-5,5 cm larg., glabras; ramo floral ereto, $40-55 \mathrm{~cm}$ compr. Flores sésseis, pistiladas e estaminadas na mesma inflorescência, estaminadas no ápice, 1-1,2 cm compr.; pistiladas $0,8-1 \mathrm{~cm}$ compr. Fruto $1,5-2 \times 1 \mathrm{~cm}$, obovoide, verde-amarelado quando maduro; mesocarpo carnoso, endocarpo duro, 1 semente.

Nomes populares: buri, imburi, pissandó, ariri, palmeirinha-anã, buti-do-campo, coco-devassoura (Lorenzi et al. 2010).

Material examinado: ao lado do aeroporto, vegetação de cerrado, 16.VII.1962, M.S. Labouriau 87 (SP); Estação Ecológica do Cerrado, 15.XII.2004, fl., fr.im., M.G. Caxambu 739 (HCF).

Allagoptera campestris ocorre na Argentina, Brasil e Paraguai (Moraes 1996). No Brasil a espécie é registrada para a Bahia, Distrito Federal, Espírito Santo, Goiás, Maranhão, Mato Grosso, Mato Grosso do Sul, Minas Gerais, Paraná e São Paulo, onde ocorre em áreas de cerrado, campos sujos e rupestres, bem como em áreas de transição (Moraes 1996; Leitman et al. 2014). No estado do Paraná, A. campestris é encontrada nas regiões remanescentes de cerrado e campos gerais, acima de $600 \mathrm{~m}$ de altitude.

Espécie facilmente distinta das demais que ocorrem no município pelo porte herbáceo, sem espinhos e pela inflorescência não ramificada (espigada). De acordo com Lorenzi et al. (2010) é uma espécie resistente ao fogo, sendo possível encontrá-la até mesmo em Cerrado com grau elevado de degradação. Atualmente é conhecida apenas uma população no município de Campo 
Mourão, formando uma população com 25-30 indivíduos na Estação Ecológica do Cerrado; no local foram observados frutos sendo consumidos por Cerdocyon thous Linnaeus, 1766 (graxaim).

3. Butia (Becc.) Becc., l'Agric. Colon. 10: 489. 1916.

3.1 Butia microspadix Burret, Notizbl. Königl. Bot. Gart. Berlin, 10: 1050, 1930.

Planta ca. $30 \mathrm{~cm}$ alt.; inerme. Caule ca. 5 $\mathrm{cm}$ compr., ca. $3 \mathrm{~cm}$ diâm., solitário, revestido pelas bases dos pecíolos das folhas deiscentes. Folhas pinatipartidas, $68-81 \mathrm{~cm}$ compr.; bainha desenvolvida, aberta, ca. $6 \mathrm{~cm}$ compr.; pecíolo $12-$ $15 \mathrm{~cm}$ compr.; raque 50-60 cm compr.; segmentos foliares 20-24 pares, dispostos em dois planos, formando "V", lanceolados, segmentos medianos $18-30 \times 0,5-1 \mathrm{~cm}$. Inflorescência interfoliar, 25-40 cm compr., ramificada até primeira ordem; bráctea peduncular $20-30 \mathrm{~cm}$ compr., 4-5 cm larg., persistente, denso revestimento tomentoso lanoso castanho; ramos florais $12-18$, semi-pêndulos, 20-40 cm compr. Flores sésseis, pistiladas e estaminadas na mesma inflorescência, dispersas aleatoriamente, estaminadas 5-7 $\mathrm{mm}$ compr.; pistiladas 4-5 mm compr. Fruto ca. $2 \mathrm{~cm}$ diâm., ovado, verde-amarelado quando maduro; mesocarpo fibroso-carnoso, endocarpo duro, 1 semente.

Nomes populares: butiazinho (Lorenzi et al. 2010).

Material examinado: aeroporto, 20.X.1973, fl., fr.im., G. Hatschbach 23943 (MBM).

Material adicional examinado: PARANÁ: Palmeira, Rio dos Papagaios, 7.XI.2004, fl., M.G. Caxambu 721 (HCF); Ponta Grossa, Buraco do Padre, 16.X.2009, fl., fr.im., M.G. Caxambu \& E.L. Siqueira 2724 (HCF).

Butia microspadix é endêmica do Brasil, de rara ocorrência nos estados de São Paulo e Paraná (Lorenzi et al. 2010; Leitman et al. 2014; Soares et al. 2014). No Paraná ocorre na vegetação remanescente de Cerrado da região de Jaguariaíva e Campo Mourão e Campos Gerais da região de Ponta Grossa.

É caracterizada pelo hábito herbáceo e pela bráctea da inflorescência revestida por denso indumento lanoso. Esta espécie foi coletada em Campo Mourão na década de 1970 (Hatschbach et al. 2005), e desde então não há mais registros de sua ocorrência, mesmo após várias excursões de campo nos remanescentes de vegetação campestres do município. Provavelmente a espécie está localmente extinta, pela perda de espaço do cerrado para os limites urbanos. A espécie também consta na Lista de Espécies Ameaçadas do Estado do Paraná, na categoria rara (Hatschbach \& Ziller 1995) e no Livro Vermelho da Flora do Brasil, na categoria vulnerável (Leitman et al. 2013).

Na região dos campos gerais do Paraná, observamos que seus frutos são consumidos por Cerdocyon thous Linnaeus, 1766 (graxaim).

3.2 Butia paraguayensis (Barb. Rodr.) L.H. Bailey, Gentes Herb. 4: 47. 1936.

Planta 0,5-2 m alt.; inerme. Estipe 35-50 cm diâm., solitário, revestido pelas bases das bainhas das folhas deiscentes. Folhas pinatipartidas, 115-135 cm compr.; bainha desenvolvida, aberta, ca. $20 \mathrm{~cm}$ compr., pecíolo ca. $15 \mathrm{~cm}$ compr., glabro, margem com projeções lenhosas afiladas; raque $80-100 \mathrm{~cm}$ compr.; segmentos foliares 30-50 pares, dispostos em dois planos, formando "V", lanceolados, segmentos medianos 30-40 × $0,7-1,4 \mathrm{~cm}$. Inflorescência interfoliar, $45-60 \mathrm{~cm}$ compr., ramificada até primeira ordem; bráctea peduncular 50-60 × 10-14 cm, persistente, lenhosa, estriada, revestida por tomento castanho; ramos florais 35-60, semi-pêndulos, 35-50 cm compr. Flores sésseis, pistiladas e estaminadas na mesma inflorescência, estaminadas no ápice, 6-7 mm compr.; pistiladas na base, ca. $10 \mathrm{~mm}$ compr. Fruto ca. $2 \mathrm{~cm}$ diâm., ovado, verde-amarelados quando maduro; mesocarpo fibroso-carnoso, endocarpo duro, 1 semente.

Nomes populares: butiá, butiá-do-cerrado, butiazeiro-do-cerrado, coco-amargoso, cocovassoura (Lorenzi et al. 2010).

Material examinado: 13.X.1965, G. Hatschbach 12954 (MBM); 9.V.1988, S. Goetzke 314 (MBM); cerrado, 20.XI.2003, fl., fr.im., M.G. Сахатbu 203 (HCF); cerrado, 2.VIII.2004, fl., M.G. Caxambu 528 (HCF, MBM); Parque Estadual Lago Azul, 28.VIII.2009, fr.im., M.G. Caxambu 2688 (HCF).

Butia paraguayensis ocorre na Argentina, Brasil, Paraguai e Uruguai (Soares et al. 2014). No Brasil, ocorre nos estados do Mato Grosso do Sul, Minas Gerais, Paraná, Rio Grande do Sul e São Paulo, associada aos cerrados de solos arenosos (Lorenzi et al. 2010; Soares et al. 2014). No Paraná, é registrada somente para os remanescentes de Cerrado do município de Campo Mourão (Hatschbach et al. 2005).

É caracterizada pelo caule espesso, todo recoberto pelos remanescentes das bainhas das 

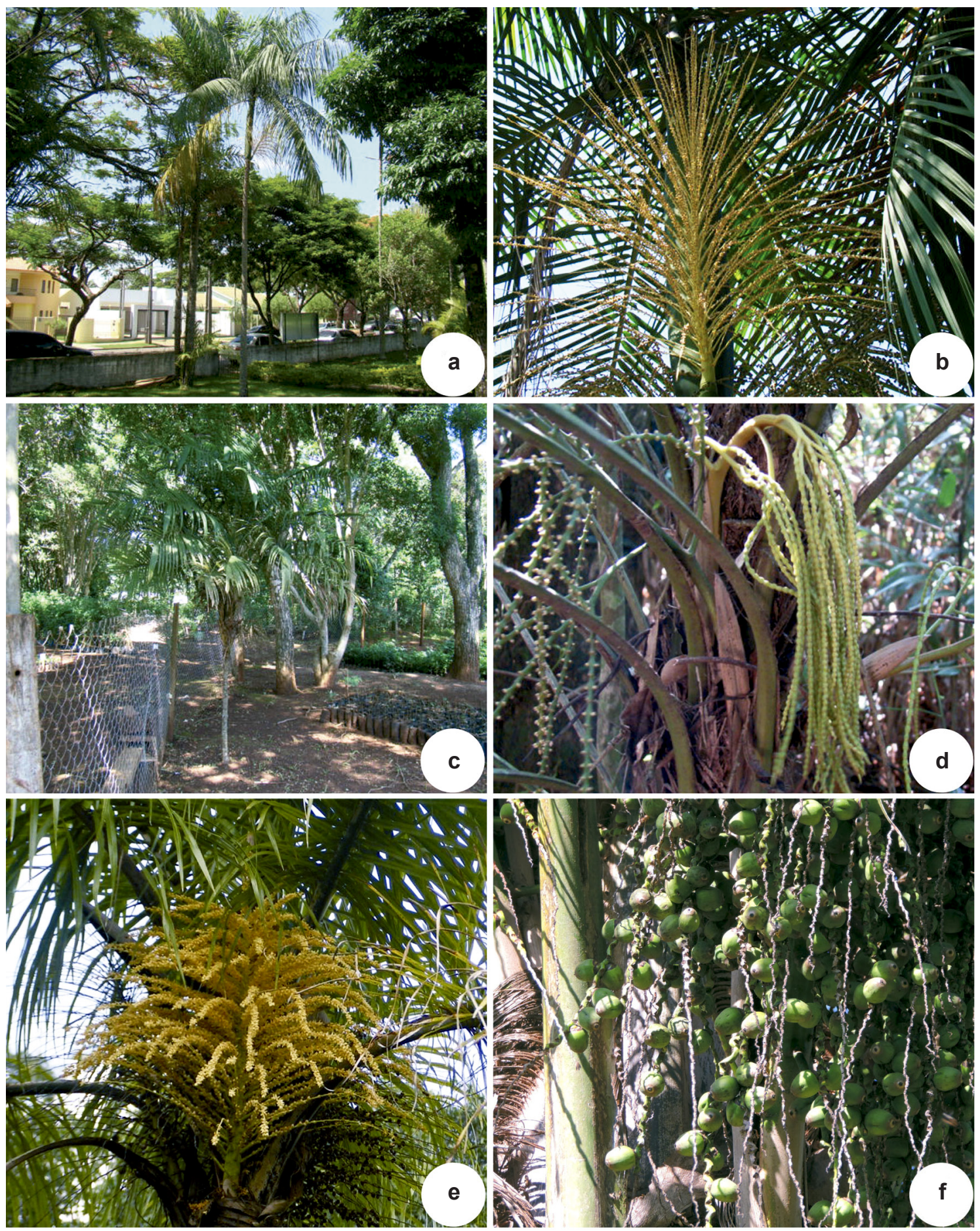

Figura 3 - a-b. Euterpe edulis - a. hábito; b. detalhe da inflorescência. c-d. Geonoma schottiana - c. hábito; d. detalhe da inflorescência. e-f. Syagrus romanzoffiana - e. detalhe da inflorescência; f. detalhe dos frutos imaturos. (Fotos: Acervo HCF).

Figure 3 - a-b. Euterpe edulis - a. habit; b. detail of inflorescence. c-d. Geonoma schottiana - c. habit; d. detail of inflorescence. e-f. Syagrus romanzoffiana - e. detail of inflorescence; f. detail of immature fruits. (Photos: HCF photo collection). 
folhas deiscentes e bráctea da inflorescência estriada. Atualmente ocorre em Campo Mourão no Cerrado e junto às áreas de Floresta Estacional do Parque Estadual Lago Azul, em pequenas populações de 10-15 indivíduos adultos, com alguns juvenis. Nestes locais foi constatado o consumo de seus frutos por Didelphis aurita Wied-Neuwied, 1826 (gambá-de-orelha-preta) e Cerdocyon thous Linnaeus, 1766 (graxaim).

Butia paraguayensis consta na categoria em perigo da Lista de Espécies Ameaçadas do Estado do Paraná (Hatschbach \& Ziller 1995).

4. Euterpe Mart., Hist. Nat. Palm. 2: 28. 1823, nom.cons.

4.1 Euterpe edulis Mart., Hist. Nat. Palm. 2(2): 33-34, fig. 32. 1824.

Planta até 13 m alt.; inerme. Estipe 15-20 cm diâm., solitário. Folhas pinatipartidas, 1,9-3,5 m compr.; bainha desenvolvida, aberta, 1-1,5 m compr., fechada, verde ou amarelada, lenhosa, glabra; raque 0,9-2 m compr.; segmentos foliares 50-70 pares, dispostos em um único plano, lanceolados, horizontais ou pêndulos; segmentos medianos 50-60 × 1,5-2 cm. Inflorescência infrafoliar, 50-65 cm compr., ramificada até primeira ordem; bráctea peduncular $45-70 \mathrm{~cm}$ compr., deiscente; ramos florais 45-100, eretos ou pêndulos, 45-60 cm compr. Flores sésseis, pistiladas e estaminadas na mesma inflorescência, distribuídas ao longo de todo o ramo floral, estaminadas 4-5 mm compr.; pistiladas 4 $-5 \mathrm{~mm}$ compr. Fruto 1-1,5 cm diâm., globoso, negro a purpúreo quando maduro; mesocarpo fibrosocarnoso, endocarpo duro, 1 semente.

Nomes populares: içara, palmito-doce, palmito-juçara, juçara, palmiteiro, ensarova, ripeira (Lorenzi et al. 2010).

Material examinado: Parque Estadual Lago Azul, 16.XII.2008, fl., M. G. Caxambu 2498 (HCF).

Euterpe edulis ocorre na Argentina, Brasil e Paraguai (Lorenzi et al. 2010). No Brasil, é espécie típica da Floresta Ombrófila Densa das regiões Sul e Sudeste, estendendo-se também para os estados da Bahia, Distrito Federal, Goiás e Mato Grosso do Sul (Lorenzi et al. 2010; Soares et al. 2014). No Paraná, a espécie é mais frequente na região da Serra do Mar e estende-se para o interior do estado, acompanhando as matas ciliares dos rios Ivaí, Iguaçu e Paraná. Em Campo Mourão ocorre nas áreas de transição da Floresta Ombrófila Mista e Floresta Estacional Semidecidual, em interior de mata. Atualmente ocorre de forma dispersa nos poucos remanescentes que restam destas formações vegetais, como o Parque Estadual Lago Azul.

Euterpe edulis é facilmente reconhecida pela presença de bainhas fechadas e lenhosas no ápice do estipe e inflorescências infrafoliares. É uma espécie de crescimento lento, sem capacidade de rebrota e dependente de florestas bem conservadas (Leitman et al. 2013), pois seu desenvolvimento se dá nos estratos inferiores das formações florestais (Klein 1979). Em toda a sua área de ocorrência tem sido submetida à intensa exploração para a extração do palmito, que exige o corte dos indivíduos adultos e retirada do meristema apical. A espécie é listada no Livro Vermelho da Flora do Brasil, na categoria vulnerável (Leitman et al. 2013).

Em campo foi observado o consumo de seus frutos por Turdus leucomelas Vieillot, 1818 (sabiá-barranco) e Penelope obscura Temminck, 1815 (jacú).

5. Geonoma Willd., Sp. Pl. 4(1): 174, 593. 1805. 5.1 Geonoma schottiana Mart., Hist. Nat. Palm. 2: 143, fig. 11a. 1826.

Planta 1,5-2 $\mathrm{m}$ alt. Estipe 2-3 cm diâm., solitário, liso, apresentando somente as cicatrizes foliares. Folhas pinatipartidas, $130-175 \mathrm{~cm}$ compr.; bainha ca. $20 \mathrm{~cm}$ compr., aberta; pecíolo 50-65 cm compr. Raque 50-90 cm compr.; segmentos foliares 30-40 pares, dispostos em um único plano, lanceolados, horizontais; segmentos medianos $20-40 \times 2-2,5 \mathrm{~cm}$, cada segmento apresentando uma nervura central e duas laterais. Inflorescência interfoliar ou infrafoliar, $50-65 \mathrm{~cm}$ compr., ramificada até segunda ordem; bráctea peduncular $25 \times 2,5 \mathrm{~cm}$, deiscente; ramos florais 20-30, pêndulos, 45-60 cm compr. Flores sésseis, pistiladas e estaminadas na mesma inflorescência, distribuídas ao longo de todo o ramo floral, estaminadas ca. $3 \mathrm{~mm}$ compr.; pistiladas ca. $3 \mathrm{~mm}$ compr. Fruto 0,8-1,2 cm diâm., globoso, negro a purpúreo quando maduro; mesocarpo fibrosocarnoso, endocarpo duro, 1 semente.

Nomes populares: aricanga-do-brejo, aricanga-do-capão, aricanga-de-folha-miúda, ouricana, guaricana (Lorenzi et al. 2010).

Material examinado: Parque Estadual Lago Azul, 5.III.2007, fl., fr.im., M.G. Сaxambu 1398 (HCF, FUEL).

Geonoma schottiana é endêmica do Brasil e ocorre em todos os estados das regiões Sudeste e Sul, acompanhando a distribuição da Floresta Ombrófila Densa, desde o nível do mar até 1600 
m de altitude (Lorenzi et al. 2010; Henderson 2011; Leitman et al. 2014). No Paraná, embora seja frequente na Floresta Ombrófila Densa, também se estende pela Floresta Ombrófila Mista, onde atinge seu limite oeste de distribuição na região de Campo Mourão e Tuneiras do Oeste.

Entre as espécies estudadas, é caracterizada pelo caule pouco espesso e liso, apresentando somente cicatrizes foliares, e pelos segmentos foliares com uma nervura central e duas laterais. Ocorre no sub-bosque, onde pode ser a espécie dominante e, ocasionalmente, em áreas abertas ou restingas, em locais periodicamente alagáveis (Lorenzi et al. 2004; Reis 2006). Em Campo Mourão ocorre de forma ocasional em áreas de contato da Floresta Ombrófila Mista e Floresta Estacional Semidecidual, sempre no interior da mata.

\section{Syagrus Mart., Palm. Fam. 18. 1824.}

6.1 Syagrus romanzoffiana (Cham.) Glassman, Fieldiana, Bot. 31: 382, 1968.

Planta 5-14 m alt. Estipe 30-40 cm diâm., solitário, liso, apresentando somente as cicatrizes foliares. Folhas pinatipartidas, 2,7-4,7 m compr.; bainha desenvolvida, aberta, ca. $20 \mathrm{~cm}$ compr., aberta; pecíolo 1-1,5 m compr.; raque 1,5-3 m compr.; segmentos foliares 50-100 pares, dispostos em grupos de 3-5, em vários planos, lanceolados; segmentos medianos 60-80 × 1-2,5 cm. Inflorescência interfoliar, 70-90 cm compr., ramificada até primeira ordem; bráctea peduncular ca. $150 \times 20 \mathrm{~cm}$, deiscente; ramos florais 50-150, pêndulos, $60-80 \mathrm{~cm}$ compr. Flores sésseis, pistiladas e estaminadas na mesma inflorescência, distribuídas ao longo de todo o ramo floral, estaminadas 1-1,3 mm compr.; pistiladas 5-6 $\mathrm{mm}$ compr. Fruto 1,5-2 cm diâm., globoso, amarelo ou alaranjado quando maduro; mesocarpo fibrosocarnoso, endocarpo duro, 1 semente.

Nomes populares: jerivá, gerivá, coqueirojerivá, jeribá, coqueiro, coco-de-catarro, cocobabão, baba-de-boi, coco-de-cachorro (Lorenzi et al. 2010).

Material examinado: Capela do Calvário, 10.IX.2005, fl., fr., H.C.L. Geraldino 95 (HCF); Parque Estadual Lago Azul, 16.II.2007, fl., M.G. Сахатbu 1376 (HCF).

Syagrus romanzoffiana ocorre na Argentina, Brasil, Paraguai e Uruguai (Lorenzi et al. 2010). No Brasil, distribui-se por todos os estados do Sudeste e Sul, estendendo-se até o sul da Bahia, Goiás e Mato Grosso do Sul (Lorenzi et al. 2010; Leitman et al. 2014), onde ocorre em Florestas Ombrófilas, Estacionais e Cerrado. No Paraná, é

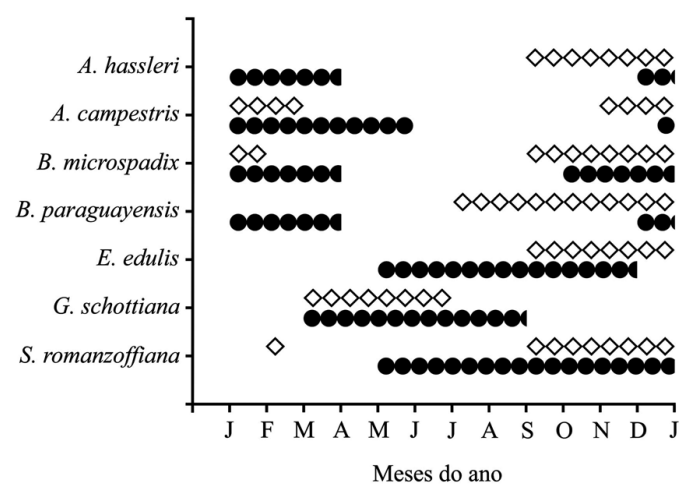

Figura 4 - Floração e frutificação das espécies nativas de Arecaceae encontradas em Campo Mourão, Paraná, Brasil. As inflorescências estão representadas por $(\diamond)$ e as infrutescências por $(\bullet)$.

Figure 4 - Flowering and fruiting period of native species of Arecaceae in Campo Mourão, Paraná, Brazil. Inflorescences are represented by $(\diamond)$ and infrutescence by $(\bullet)$.

encontrada em todo o território, sendo mais comum na Floresta Estacional Semidecidual e Floresta Ombrófila Mista.

Syagrus romanzoffiana é uma palmeira alta, que normalmente se destaca na paisagem, caracteriza-se pelo estipe espesso e liso, somente com as cicatrizes foliares, pelas folhas com segmentos dispostos em vários planos na raque e pela inflorescência longa, com muitos ramos florais. Cresce no interior das matas, mas pode comportar-se como planta pioneira (Reitz \& Klein 1974) em capões ou, ocasionalmente nos afloramentos de rocha.

Em Campo Mourão é a espécie de palmeira que outrora foi a mais abundante e, apesar da intensa alteração na paisagem, é ainda encontrada com maior frequência nos remanescentes do município. Em campo, foi observado o consumo dos frutos por Tapirus terrestris Linnaeus, 1758 (anta), Cerdocyon thous Linnaeus, 1766 (graxaim), Sapajus nigritus Goldfuss, 1809 (macaco-prego), Tayassu pecari Link, 1795 (queixada) e Penelope obscura Temminck, 1815 (jacú).

\section{Considerações finais}

A maioria das espécies confirmadas para Campo Mourão são características de áreas de Cerrado e Campo: Acrocomia hassleri, Allagoptera campestris, Butia microspadix e Butia paraguayensis. A maior degradação desta formação vegetal no município também resultou no quase 
extermínio das populações. Acrocomia hassleri e B. paraguayensis, que no Paraná são registradas exclusivamente em Campo Mourão, são somente conhecidas por poucos exemplares e correm o risco de desaparecer, caso constatado para a espécie $B$. microspadix. Recomendam-se medidas urgentes no que diz respeito à proteção das áreas remanescentes de Cerrado do município, como forma de manter estas espécies no Paraná, além de iniciativas que visem à produção de mudas para o plantio em áreas degradadas de Cerrado ou em arboretos, como medida de conservação adicional.

As demais espécies estão relacionadas às formações florestais da Floresta Ombrófila Mista (Geonoma schottiana) e da Floresta Estacional Semidecidual (Euterpe edulis e Syagrus romanzoffiana). Exceto $S$. romanzoffiana, que é relativamente abundante na região, as outras duas espécies também apresentam rara ocorrência e necessitam de medidas que garantam a manutenção de suas populações.

A ocorrência de Acrocomia emensis não foi confirmada para o Paraná.

\section{Agradecimentos}

À equipe de coleta do Herbário da Universidade Tecnológica Federal do Paraná Campus Campo Mourão (HCF), o auxílio em campo e o apoio em todo o trabalho; ao professor Celso Aparecido Gandolfo (in memorian), o valioso apoio a pesquisa e à Faculdade de Ciências e Letras de Campo Mourão (FECILCAM), a autorização para coleta de material botânico na Estação Ecológica do Cerrado de Campo Mourão.

\section{Referências}

Alonso, A.; Dallmeier, F.; Granek, E. \& Raven, P. 2001. Biodiversity: connecting with the tapestry of life. Monitoring and assessement of biodiversity program and president's committe of advisors on science and technology. Smithsonian Institution, Washington D.C. 31p.

Bates, D.M. 1988. Utilization pools: a framework for comparing and evaluation the economic importance of palms. Advances in Economic Botany 6: 56-64.

EMBRAPA-Empresa Brasileira de Pesquisas Agropecuárias. 1999. Centro Nacional de Pesquisa de Solos. Sistema brasileiro de classificação de solos. Embrapa Solos, Rio de Janeiro. 421p.

Gonçalves, E.G. \& Lorenzi, H. 2007. Morfologia vegetal: organografia e dicionário ilustrado de morfologia das plantas vasculares. Instituto Plantarum, Nova Odessa. 416 p.
Guerreiro, R.L.; Parolin, M. \& Marcotti, T.C.B. 2011. Distribuição e recuperação da vegetação do Cerrado e remanescentes na cidade de Campo Mourão, Paraná, Brasil. Boletim de Geografia 29: 113-122.

Hatschbach, G.G \& Ziller, S.R. 1995. Lista vermelha de espécies ameaçadas de extinção no estado do Paraná. Secretaria Estadual do Meio Ambiente de Curitiba, Curitiba. 139 p.

Hatschbach, G.G. Linsingen, L.; Uhlmann, A.; Cervi, A.C.; Sonehara, J.S. \& Ribas, O.S. 2005. Levantamento florístico do Cerrado (savana) paranaense e vegetação associada. Boletim do Museu Botânico Municipal 66: 1-40.

Henderson, A. 2011. A revision of Geonoma (Arecaceae). Phytotaxa 17: 1-271.

IBGE - Instituto Brasileiro de Geografia Estatística. 1997. Divisão Municipal do Instituto Brasileiro de Geografia Estatística. Disponível em <http://www. ibge.gov.br>. Acesso em 20 junho 2010.

Jiménez, B. \& Knapp, S. 1998. Palms of the Reserva Natural del Bosque Mbaracayu, Paraguay (Mbaracayu Natural Forest Reserve). Principes 42: 65-79.

Klein, R.M. 1979. Ecologia da flora e vegetação do Vale do Itajaí. Sellowia 31: 103-164.

Leitman, P.; Judice, D.M.; Barros, F.S.M. \& Prieto, P.V. 2013. Arecaceae. In: Martinelli, G. \& Moraes, M.A. (orgs). Livro Vermelho da Flora do Brasil. Instituto de Pesquisas Jardim Botânico do Rio de Janeiro, Rio de Janeiro. Pp. 187-195

Leitman, P.; Henderson, A.; Noblick, L. \& Soares, K. 2014. Arecaceae. In: Lista de Espécies da Flora do Brasil. Jardim Botânico do Rio de Janeiro. Disponível em $<$ http://floradobrasil.jbrj.gov.br/jabot/floradobrasil/ FB53>. Acesso em 28 março 2014.

Lorenzi, H.; Souza, H.M.; Madeiros-Costa, J.T.; Cerqueira, L.S.C. \& Ferreira, E. 2004. Palmeiras brasileiras e exóticas cultivadas. Instituto Plantarum, Nova Odessa. 416p.

Lorenzi, H.; Sartori, S.; Bacher, L.B. \& Lacerda, M. 2006. Frutas brasileiras e exóticas cultivadas (de consumo in natura). Instituto Plantarum, Nova Odessa. 672p.

Lorenzi, H.; Noblick, L.R; Kahn, F. \& Ferreira, E. 2010. Arecaceae (Palmeiras). Instituto Plantarum, Nova Odessa. 368p.

Maack, R. 1981. Geografia Física do Estado do Paraná. $2^{\mathrm{a}}$ ed. Livraria José Olympio, Rio de Janeiro. 442 p.

Miranda, I.P.A.; Rabelo, A.; Bueno, C.R.; Barbosa, E.M. \& Ribeiro, M.N.S. 2001. Frutos de palmeiras da Amazônia. Instituto Nacional de Pesquisa da Amazônia, Manaus. 120p.

Moraes, M.R. 1996. Allagoptera (Palmae). Flora Neotropica 73: 1-34.

Reis, R.C.C. 2006. Palmeiras (Arecaceae) das restingas do estado do Rio de Janeiro, Brasil. Acta Botanica Brasilica 20: 501-512. 
Reitz, R. \& Klein, R.M. 1974. Flora Ilustrada Catarinense: Palmeiras (parte I). Herbário Barbosa Rodrigues, Itajaí. 189p.

Roderjan, C.V.; Galvão, F.; Kuniyoshi, Y.S.; \& Hatschback, G. 2002. As unidades fitogeográficas do estado do Paraná. Ciência \& Ambiente 24: 75-92.

Romariz, D.A. 1996. Aspectos da vegetação do Brasil. $2^{\mathrm{a}}$ ed. Edição da Autora, São Paulo. 60p.
Santos, G.B.; Marques, M.I.; Adis J. \& Musis, C.R. 2003. Artrópodos associados à copa de Attalea phalerata Mart. (Arecaceae), na região do Pantanal de Poconé-MT. Revista Brasileira de Entomologia 47: 211-224.

Soares, K.P.; Longhi, S.J.; Witeck Neto, L \& Assis, L.C. 2014. Palmeiras (Arecaceae) no Rio Grande do Sul, Brasil. Rodriguésia 65: 113-139. 